\title{
Possible role of vitamin $D$ in Covid-19 infection in pediatric population
}

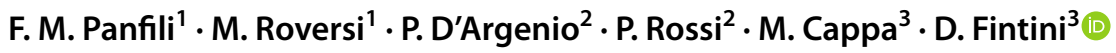

Received: 7 May 2020 / Accepted: 3 June 2020 / Published online: 15 June 2020

(C) Italian Society of Endocrinology (SIE) 2020

\begin{abstract}
Purpose Covid-19 is a pandemic of unprecedented proportion, whose understanding and management is still under way. In the emergency setting new or available therapies to contrast the spread of COVID-19 are urgently needed. Elderly males, especially those affected by previous diseases or with comorbidities, are more prone to develop interstitial pneumonia that can deteriorate evolving to ARDS (acute respiratory distress syndrome) that require hospitalization in Intensive Care Units (ICUs). Even children and young patients are not spared by SARS-CoV 2 infection, yet they seem to develop a milder form of disease. In this setting the immunomodulatory role of Vitamin D, should be further investigated. Methods: We reviewed the literature about the immunomodulatory role of Vitamin D collecting data from the databases Medline and Embase.

Results Vitamin D proved to interact both with the innate immune system, by activating Toll-like receptors (TLRs) or increasing the levels of cathelicidins and $\beta$-defensins, and adaptive immune system, by reducing immunoglobulin secretion by plasma cells and pro-inflammatory cytokines production, thus modulating T cells function. Promising results have been extensively described as regards the supplementation of vitamin D in respiratory tract infections, autoimmune diseases and even pulmonary fibrosis.

Conclusions In this review, we suggest that vitamin D supplementation might play a role in the prevention and/or treatment to SARS-CoV-2 infection disease, by modulating the immune response to the virus both in the adult and pediatric population.
\end{abstract}

Keywords Covid19 $\cdot$ SarsCov2 $\cdot$ Vitamin D $\cdot$ Pediatric $\cdot$ Pneumonia $\cdot$ Immunity

\section{Introduction}

The recent epidemic of Covid-19 has rapidly become an emergency threat for the health systems of all infected countries by overloading the medical facilities and intensive care units and causing thousands of deaths. In order to allow the National Health Systems to organize and set more beds, devices and medical personnel, the local governments have

Filippo M. Panfili and Marco Roversi have contributed equally to the manuscript.

D. Fintini

danilo.fintini@opbg.net

1 Pediatric Academic Department, University of Rome Tor Vergata, Rome, Italy

2 Division of Immunology and Infectious Diseases, University-Hospital Pediatric Department (DPUO), Bambino Gesù Children's Hospital, IRCSS, Rome, Italy

3 Endocrinology Unit, University-Hospital Pediatric Department (DPUO), Bambino Gesù Children's Hospital, IRCSS, Rome, Italy taken extraordinary measures to restrain the spread of the epidemic, including limitation of individual movements, shutdown of all less necessary economic activities and isolation of areas and cities where the epidemic has clustered. Given the dire circumstances, the efforts of the researchers have been focused on the prevention and treatment of this disease. Nonetheless, while the development of new drugs or vaccines would take a long time before human testing and commercialization, clinical trials on available pharmaceuticals with a potential effect against Covid-19 could more easily yield useful results and, as a matter of fact, are already being performed. Vitamin D is usually known for its role in the maintenance of bone health and calcium-phosphorus metabolism, yet many other roles of this hormone have been recently discovered, such as modulation of the immune response in both infectious and autoimmune diseases. Just recently, it is being hypothesized that vitamin D supplementation could be used as a preventive or event therapeutic option in Covid-19, but more studies are needed to validate this association. In the following, we describe vitamin D immunomodulatory role and effect on some infectious 
and autoimmune diseases that might share similarities with Covid-19, based on the current and future understanding of the pathogenesis of this infection.

\section{The epidemic of Covid-19}

In December 2019, an epidemic of pneumonia caused by a novel virus later identified as severe acute respiratory syndrome coronavirus 2 (SARS-CoV-2) started in the city of Wuhan, Hubei province, China. Recently, the World Health Organization (WHO) has declared coronavirus disease 2019 (Covid-19), a pandemic of global health concern. Most people infected by SARS-CoV-2 develop interstitial pneumonia with ground-glass opacities at the CT scan, while a minority of patients develop acute respiratory distress syndrome (ARDS), and need hospitalization in Intensive Care Units (ICUs).

As of April 13, 2020, a total of 1,773,084 laboratoryconfirmed cases and 111,652 deaths have been documented [1]. In Italy, the first European country to deal with a rapid increase in the number of Covid-19 cases in the last month, the epidemic is cornering the National Health System (SSN), which usually provides high-level and free-for-all health care. Despite the total shutdown of the country to limit the spread of the epidemic and the increasing of ICU personnel, devices, and beds are timely met, the recent estimates predict a gloomy development of the epidemic, with clinical facilities at their maximum load and intensive care specialists forced to allocate the life-saving care to the youngest and fittest [2]. That is, making the uncomfortable choice between who lives and who dies.

The demographics of the Covid-19 outbreak proves that elderly males, with or without comorbidities, are the most severely affected across all populations. In a large report of 72,314 cases from the Chinese Center for Disease Control and Prevention [3], 87\% of cases were aged 30-79 years and $3 \%$ were aged 80 years or more, with a case-fatality rate of $8 \%$ and $14.8 \%$, respectively. Critical disease requiring admission in ICU and mechanical ventilation was observed in $5 \%$ of all cases, with a case-fatality rate of $49 \%$. In a sample of 1099 laboratory-confirmed cases of Covid-19 [4] $41.7 \%$ of patients were females and $0.9 \%$ of patients were 14 years old or younger. Although children appear to be the least affected across all ages, they might still be responsible of the transmission of the virus. In a cohort of 171 pediatric cases of Covid-19 [5] up to $15.8 \%$ of patients did not have any symptoms of infection or radiologic features of pneumonia and $7 \%$ of these patients had radiologic features of pneumonia without presenting any clinical sign. In a report on 2.143 pediatric cases of Covid-19 more than $90 \%$ of patients with clinically or laboratory diagnosed infection had asymptomatic, mild, or moderate disease. Half of the
$10 \%$ critical cases of Covid-19 in this study were less than 1 year of age [6].

\section{Vitamin D}

Most people depend on sunlight exposure to produce the required amount of vitamin $\mathrm{D}$ [7].

Differences in sunlight-dependent production of vitamin $D$ is greatly influenced by season, latitude, time of day, skin pigmentation, sunscreen use, and age, with the elderly generating $25 \%$ of the vitamin D produced by younger ones in the same amount of time. As very few nutrients naturally contain vitamin $\mathrm{D}$, dietary intake of vitamin $\mathrm{D}$ is generally insufficient. Thus, fortification of food and/or oral supplementation is often necessary. In adults, vitamin D supplementation is recommended for all ages (600 UI/day from 19 to 70 years of age; $800 \mathrm{UI} /$ day $>70$ years of age; up to $1500 / 2000 \mathrm{UI} /$ day to maintain a blood level of vitamin D above $30 \mathrm{ng} / \mathrm{mL}$ ), with a higher dosage required for pregnant or lactating women and subjects at risk of osteoporosis [8]. In the pediatric population, vitamin D supplementation (400 UI/day from birth to 12 months of age and $600 \mathrm{UI} /$ day beyond 12 months of age) is usually recommended for the prevention of rickets and osteomalacia [9].

The ultraviolet $\mathrm{B}$ radiation is absorbed by 7-dehydrocholesterol in the skin, leading to its conversion to previtamin D3, which is rapidly transformed into vitamin D3 (cholecalciferol). The molecule then undergoes further processing in the liver [25-hydroxycholecalciferolorcalcifediol] by cytochrome CYP2R1 and in the kidney (1,25-dihydroxy cholecalciferol or calcitriol) by cytochrome CYP27B1, before reaching its cellular targets. Here, the activated vitamin D binds to the nuclear vitamin D receptor (VDR) and forms an heterodimeric complex with the retinoic acid $\mathrm{X}$ receptor that recognizes specific DNA sequences, known as vitamin D responsive elements (VDRE), resulting in the expression of the vitamin $\mathrm{D}$ responsive genes via a variety of transcriptional factors (Fig. 1).

\section{Immunomodulatory and antiviral role of vitamin D}

Although vitamin D is usually acknowledged for the maintenance of bone health and calcium-phosphorus metabolism, many other roles of this hormone have been recently discovered, such as stimulation of insulin production, effects on myocardial contractility, prevention of inflammatory bowel disease (IBD), and promotion of thyroid-stimulating hormone (TSH) secretion. Furthermore, the immunomodulatory role of vitamin $\mathrm{D}$ has been the subject of several studies [10]. To date, it is known that the VDR activation can 


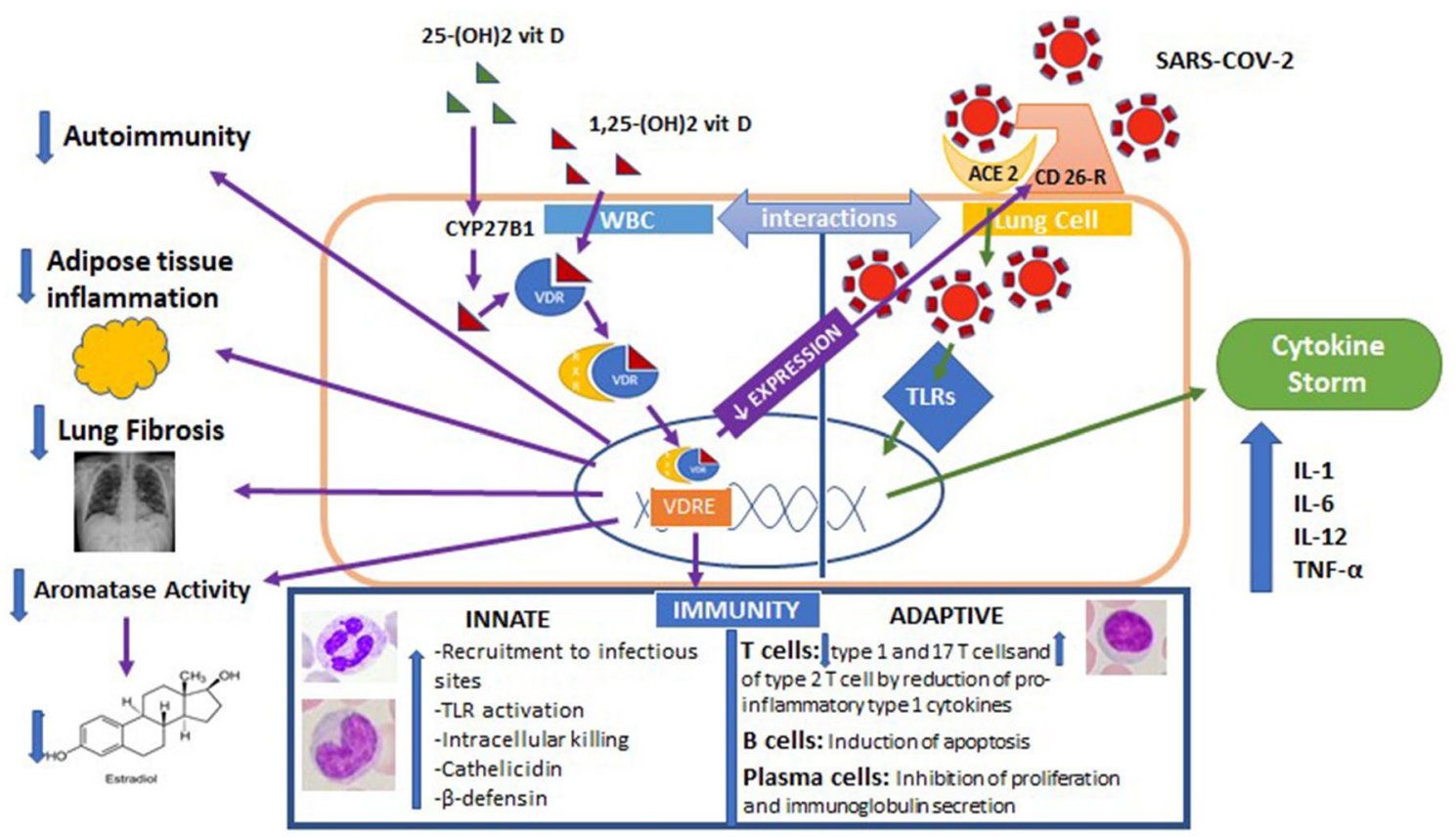

Fig. 1 In this picture, we resumed on the left side the principal functions of vitamin D. In particular, we enlightened the anti-proliferative and anti-inflammatory function on adipose tissue, the anti-fibrotic effect on lung tissue, the inhibition of the aromatase enzyme with subsequently reduction in estradiol, the preventing role in developing autoimmune diseases and its immunomodulatory role on the innate and adaptive immune systems. On the right side, it is shown the

regulate the expression of more than 900 genes, many of which are involved in innate and adaptive immunity. VDR is expressed in almost all immune cells, including activated CD4+ and CD8+ T cells, B cells, and antigen-presenting cells, such as macrophages and dendritic cells. The receptor acts as a modulator of innate and adaptive immunity [11]. It is also known that vitamin $D$ enhances the expression of two antimicrobial peptides called cathelicidin and $\beta$-defensin, and that play a key role in innate immunity $[12,13]$. These peptides are involved in direct microbicidal effects and have also shown pleiotropic effects in inducing immunomodulatory responses to pathogen stimuli. In particular, human cathelicidin peptide LL37 exhibits a variety of effects, through interacting with formyl peptide receptor-like 1 (FPRL1), recruiting neutrophils, monocytes, and T cells to infectious sites. It also promotes apoptosis of infected cells and showed a potent antiviral effects on a variety of viruses, such as HIV-1, influenza viruses, HSV1-2, rhinovirus, and HCV [14]. A number of studies reported a high prevalence of vitamin D deficiency among HIV-infected individuals. More specifically, faster HIV progression and severity, lower CD4+ counts, increased risk of mortality, and increased vulnerability to Mycobacterium tuberculosis were reported [15]. Although the effect of normal to high levels of vitamin D on increasing CD4+ count is still unclear, a recent review
"Cytokine Storm" caused by SARS-Cov-2. We highlighted also the possible interaction role of DPP-4/CD 26-R, reduced by supplementation of vitamin D with SARS-Cov-2. ACE-2 angiotensin-converting enzyme-2, $R X R$ retinoid $\mathrm{X}$ receptor, TLRs toll-like receptors, $V D R$ vitamin $\mathrm{D}$ receptor, $V D R E$ vitamin $\mathrm{D}$ response element, $W B C$ white blood cell

proved that vitamin $\mathrm{D}$ plays an important role in reducing the immune activation of HIV-infected patients. In particular, the paper reports that supplementation with a daily dose of vitamin D between 4000-7000 IU for at least 12 weeks can reduce the expression of CD38 and Ki67 in CD8+ T lymphocytes, inflammatory monocytes (CD14+CD16+), as well as the expression of PD1 + (an exhaustion marker) in $\mathrm{CD} 4+\mathrm{T}$ cells, with an increase in $\mathrm{CD} 4+/ \mathrm{CD} 8+\mathrm{T}$ cell ratio. This leads to the important assumption that brisk supplementation in vitamin D-deficient HIV-infected patients could help reduce chronic inflammation and comorbidities [16] that are still frequent among these patients despite the constant amelioration of combination antiretroviral therapy (cART) [17]. Human cathelicidin peptide LL37 also modulates the recognition of viral dsRNA by Toll-like receptor 3 (TLR 3). It is known that activation of Toll-like receptors (TLRs) generate antimicrobial activity against intracellular pathogens and it has been demonstrated that TLR activation expressed by human macrophages can upregulate the expression of vitamin D receptor and vitamin D-1-hydroxylase genes, leading to the production of antimicrobial peptide (cathelicidin) and stimulate the intracellular killing of $\mathrm{Myco-}$ bacterium tuberculosis [13]. Vitamin D also promotes selftolerance by shifting the cytokine patterns from a Th- 1 to a Th-2 environment. This results in a reduction in Th1- and 
Th17-stimulating cytokines with depletion of Th-17 cells (which are known to be linked to tissue damage and inflammation) and upregulation of regulatory type-2 (T reg) cells [18]. It has also been demonstrated that vitamin D is capable of inducing autophagy and apoptosis in infected cells, throughout several mechanisms [14]. Finally, 25-hydroxyvitamin $\mathrm{D}$ and 1,25(OH)2D also modulate T-cell immunity, reducing pro-inflammatory type 1 cytokines (such as, IL-8, IFN- $\gamma$, IL-12, IL-6, TNF- $\alpha$, and IL-17) and increasing antiinflammatory type 2 cytokines (such as, IL-4, IL-5, and IL-10) [19]. More specifically, 1,25(OH)2D inhibits proliferation of plasma cell and immunoglobulin secretion, and it induces B cell apoptosis [20]. In summary, many studies have demonstrated the immunomodulatory influence of vitamin $\mathrm{D}$ both in adult and pediatric patients, by enhancing and coordinating the innate and adaptive response in different pathologic conditions (Table 1).

\section{Vitamin $D$ in respiratory tract infections}

Several studies have demonstrated that higher levels of vitamin D are associated with better prognosis and outcome in infectious diseases [12]. Indeed, vitamin D has been extensively studied as a putative preventive and therapeutic agent for acute respiratory tract infections (ARTIs) in both adults and children, especially in developing and low-income countries, owing to its safety and low cost. As a matter of fact, pneumonia is the leading cause of death in children in the world [21]. A great number of studies have hypothesized a positive correlation between vitamin D deficiency and the risk of developing ARTIs [22]. However, the link between vitamin $\mathrm{D}$ deficiency and acute respiratory infections occurring during the winter season, despite being frequently brought up in the literature, has not been unequivocally confirmed [23]. Moreover, discrepancies between different age groups have been observed. Vitamin D supplementation, as already described, seems to decrease proinflammatory cytokines in the lung via modulation of both macrophages and T lymphocytes activity [24]. In a recent meta-analysis, including 25 randomised controlled studies (RCTs), it has been demonstrated that vitamin $\mathrm{D}$ supplementation reduced the risk of developing acute respiratory tract infections, with a higher protective effect in those who received weekly vitamin D supplementation or in those with low levels of vitamin D at baseline (25-hydroxyvitamin D levels $<25 \mathrm{nmol} / \mathrm{L}$ ) [25]. While it is supposed that serum levels of vitamin D between $20 \mathrm{ng} / \mathrm{mL}$ and $50 \mathrm{ng} / \mathrm{mL}$ should be adequate to provide an immunomodulatory effect, there has been great uncertainty on the vitamin D supplementation regimen to adopt [26]. A recent systematic review studied the role of vitamin $\mathrm{D}$ as an adjunctive therapy to antibiotics in acute childhood pneumonia. It included seven RCTs conducted in low-income countries that involved 1529 children. Nonetheless, owing to the different supplementation regimens adopted for each study and the lack of reporting on the etiology of pneumonia, only low- to very low-quality evidence was made available [27]. In fact, its role as possible adjuvant to antibiotics treatment of acute childhood pneumonia has already been undetermined in a previous Cochrane review [28]. A more recent study also showed how high-dose vs standard-dose wintertime vitamin D supplementation did not reduce viral upper respiratory tract infections in young healthy children [29]. Nonetheless, the ineffectiveness of vitamin $\mathrm{D}$ in the younger might be due both to the lower prevalence of vitamin D deficiency, when compared with the elderly, and to a putative threshold effect of vitamin D in preventing ARTi. It has been, indeed, demonstrated that the negative correlation between levels of vitamin D and respiratory tract infections, should be attributed to its active form (1,25-OH2-vit D); therefore, restoring the levels of inactive vitamin D might not be sufficient in some patients, like those affected by chronic kidney or liver disease [30]. Interestingly, it has also been demonstrated that vitamin D supplementation in patients with ventilator-associated pneumonia (VAP) can significantly reduce IL-6, that can be considered a prognostic marker, and the mortality rate in patients treated with vitamin $\mathrm{D}$ was significantly lower than that of the placebo group. The authors concluded suggesting the administration of vitamin $\mathrm{D}$ at a high intramuscular dose (300.000 UI) as an adjunct to the standard treatment of VAP patients [31].

\section{Vitamin $D$ in autoimmune diseases}

In a variety of animal models pretreatment with 1,25-OH2-D proved effective in mitigating or preventing the onset of type 1 diabetes mellitus (DM1), multiple sclerosis (MS), rheumatoid arthritis (RA), systemic lupus erythematosus (SLE), Crohn's disease, thyroiditis, psoriasis, polymyalgia rheumatica, and autoimmune gastritis [7, 32]. An interesting study conducted on 12.555 subjects showed a statistically significant correlation between vitamin D status and development of autoimmune disease in Danish population [33]. Interestingly, in another study specific allelic variants of VDR (especially BsmI, ApaI, TaqI, and FokI polymorphism genotypes) have been associated with higher susceptibility to develop an autoimmune disease (i.e., BsmI and FokI polymorphism for SLE or ApaI, BsmI, and TaqI polymorphisms for RA) $[34,35]$. This is of particular interest and it could explain the variability of responses to vitamin $\mathrm{D}$ supplementation in autoimmune and infectious diseases across the different regions of the world [36]. A significant inverse correlation was reported between disease activity and serum vitamin $\mathrm{D}$ concentration in SLE [37]. A preventive role of vitamin D 
Table 1 Effects of vitamin D supplementation on the immune system and other different conditions

\begin{tabular}{|c|c|c|c|}
\hline (A) Immune system component & \multicolumn{2}{|r|}{ Effect } & \multirow{2}{*}{$\frac{\text { References }}{[12,13,19]}$} \\
\hline T cells & & $\begin{array}{l}\downarrow \text { Th } 1 / \text { Th } 17 \text { T and } \uparrow \text { Th } 2 \\
\downarrow \text { IL-8, IFN- } \gamma \text {, IL-12, IL-6, TNF- } \alpha \text {, IL-17 } \\
\uparrow \text { IL-4, IL-5, IL-10 } \\
\text { Recognition of viral dsRNA by Toll-like receptor } 3 \text { (TLR 3) }\end{array}$ & \\
\hline \multicolumn{2}{|l|}{ B cells } & $\uparrow$ Apoptosis & {$[20]$} \\
\hline \multicolumn{2}{|l|}{ Plasma cells } & $\downarrow$ Proliferation and immunoglobulin secretion & {$[20]$} \\
\hline \multicolumn{2}{|c|}{ Neutrophils, monocyte-macrophages and dendritic cells) } & $\begin{array}{l}\text { Recruitment to infectious sites, } \uparrow \text { TLR } \\
\uparrow \text { Intracellular killing of M. Tuberculosis (macrophages) }\end{array}$ & {$[13]$} \\
\hline \multicolumn{2}{|l|}{ Infected cells } & $\uparrow$ Autophagy and apoptosis & {$[13,14]$} \\
\hline \multicolumn{2}{|c|}{$\begin{array}{l}\text { Antimicrobial peptides (human cathelicidin peptide LL37 and } \\
\beta \text {-defensin) }\end{array}$} & Increased & {$[12,13]$} \\
\hline (B) Respiratory tract infections & Effect & Effect on disease & References \\
\hline Acute respiratory tract infections & $\begin{array}{l}\downarrow \text { Proinflammatory cytokines in the lung via modulation } \\
\text { of both macrophages and T lymphocytes activity }\end{array}$ & $\begin{array}{l}\text { ines in the lung via modulation } \downarrow \text { Risk in developing the disease } \\
\text { ld T lymphocytes activity }\end{array}$ & {$[23,24]$} \\
\hline Acute childhood pneumonia & - & No significant effect & {$[27,28]$} \\
\hline VAP & $\downarrow$ IL-6 & $\downarrow$ Mortality & {$[31]$} \\
\hline \multicolumn{2}{|l|}{ (C) Autoimmune disease } & Effect on disease & References \\
\hline \multicolumn{2}{|l|}{ Diabetes mellitus type 1} & $\begin{array}{l}\text { Prevention of onset, } \downarrow \text { serum levels of antibodies, delayed } \beta \text { cell destruc- } \\
\text { tion in the early stages of the disease }\end{array}$ & {$[8,32]$} \\
\hline \multicolumn{2}{|l|}{ Multiple sclerosis } & Prevention of onset & {$[8,32]$} \\
\hline \multicolumn{2}{|l|}{ Rheumatoid arthritis } & Prevention of onset, reduced disease activity & $\begin{array}{l}{[8,32,35,40,} \\
\quad 41]\end{array}$ \\
\hline \multicolumn{2}{|l|}{ Systemic lupus erythematosus } & Prevention of onset, reduced disease activity & {$[8,32,37]$} \\
\hline \multicolumn{2}{|l|}{ Crohn's disease } & Prevention of onset & {$[8,32]$} \\
\hline \multicolumn{2}{|l|}{ Thyroiditis } & Prevention of onset & {$[8,32]$} \\
\hline \multicolumn{2}{|l|}{ Psoriasis } & Prevention of onset & {$[8,32]$} \\
\hline \multicolumn{2}{|l|}{ Polymyalgia rheumatica } & Prevention of onset & {$[8,32]$} \\
\hline \multicolumn{2}{|l|}{ Autoimmune gastritis } & Prevention of onset & {$[8,32]$} \\
\hline \multicolumn{2}{|l|}{ Systemic sclerosis } & $\begin{array}{l}\text { Downregulation of TGF- } \beta / \text { Smad signaling (putative antifibrotic effect in } \\
\text { the early stages of the disease) }\end{array}$ & [39] \\
\hline (D) Pulmonary fibrosis & Effect & Effect on disease & References \\
\hline IL-beta & $\begin{array}{l}\text { Antag } \\
\text { bleol }\end{array}$ & $\begin{array}{l}\text { Antagonism of pulmonary fibroblast cell activity in murine model of } \\
\text { bleomycin-induced lung fibrosis }\end{array}$ & [47] \\
\hline $\begin{array}{l}\text { Hydroxyproline, col1a1, col3a1 and } \\
\text { alfa-SMA mRNAs }\end{array}$ & Preven & Prevention of bleomycin-induced lung fibrosis in a murine model & [48] \\
\hline
\end{tabular}

(A) In this section of the table, we resumed the principal immunoregulatory actions of vitamin D. Specifically, we focused the attention on T cells: downregulation of type 1 and $17 \mathrm{~T}$ cells and upregulation of type $2 \mathrm{~T}$ cell by reduction in pro-inflammatory type 1 cytokines (IL-8, IFN- $\gamma$, IL-12, IL-6, TNF- $\alpha$, and IL-17) and increase in anti-inflammatory type 2 cytokines (IL-4, IL-5, and IL-10), recognition of viral dsRNA by Tolllike receptor 3 (TLR 3). On B cells, vitamin D showed a pro-apoptotic function. Plasma cells show a reduction in proliferation and immunoglobulin secretion. Neutrophils, monocyte-macrophages, and dendritic cells are recruited to infectious sites and they show an augmented intracellular killing of Mycobacterium tuberculosis (macrophages). The infected cells undergo, more easily in autophagy and apoptosis. Finally, vitamin $\mathrm{D}$ can increase antimicrobial peptides, such as human cathelicidin peptide LL37 and $\beta$-defensin. (B) In this section, it is showed how vitamin D impact on ARTi reducing proinflammatory cytokines and modulating the action of macrophages and T cells activity with reduction in the risk of developing the disease. No clear effects have been demonstrated on childhood pneumonia. Reduction in IL-6 and mortality have been reported on VAP. (C) Vitamin D has a clear action on autoimmune disease, specifically it can reduce the risk in developing: diabetes mellitus type 1, multiple sclerosis, rheumatoid arthritis, systemic lupus erythematosus, Crohn's disease, thyroiditis, psoriasis, polymyalgia rheumatica, autoimmune gastritis, and systemic sclerosis. (D) In the last part of the table, we focused on the putative anti-fibrotic role of vitamin D by its capacity in reduction in IL-beta, reduce the pulmonary fibroblastic activity and a reduction in hydroxyproline, col1a1, col3a1, and alfa-SMA mRNAs, with the prevention of bleomycin-induced lung fibrosis in a murine model

has also been demonstrated in DM1. In this autoimmune disease using calcitriol supplementation reduces serum levels of antibodies and slows the progression of $\beta$ cell destruction down in the early stages of the disease [38], Interestingly, it has also been demonstrated that in Systemic Sclerosis (SSc) [39] the VDR could act as a negative regulator of TGF- $\beta$ / 
Smad signaling, thus making vitamin D a putative antifibrotic treatment in the early stages of the disease. Although the immunoregulatory function of activated vitamin D has been widely demonstrated, its role in modulating disease activity in patients with autoimmune diseases, such as rheumatoid arthritis was only recently showed [40, 41]. In a German study on a selected cohort of patients with juvenile idiopathic arthritis (JIA), vitamin D levels not only proved to be lower than those of their peers from the general population, but were also found to be inversely correlated with disease activity and the risk of progression to an extended disease course and/or JIA-associated anterior uveitis [42]. However, many other studies could not demonstrate a significant inverse correlation between vitamin D levels and JIA disease activity, probably owing to the diverse geographical origins of the patients and the lack of an established single measure that could serve as an accurate indicator of childhood disease activity [43]. Although a sudden increase in the incidence of Kawasaki disease (KD) was noted in the province of Bergamo, Italy, which was profoundly affected by the Covid-19 epidemics [44], another study reported a significant severe vitamin D deficiency in a cohort of 79 children with KD as compared to healthy controls, and low levels of vitamin D seems to correlate to the risk in developing coronary artery aneurysms $(p=0.005)$ and non-aneurysmatic cardiovascular lesions $(p<0.05)$ [45]. Moreover, vitamin $\mathrm{D}$ deficiency has been associated with resistance to intravenous immunoglobulin in $\mathrm{KD}$ (defined as persistent or recrudescent fever $\geq 36 \mathrm{~h}$ after the completion of the initial infusion), suggesting a potent immunomodulatory role of this vitamin [46]. Of note, most of the aforementioned studies could not define the optimal concentration of $25(\mathrm{OH})$ $\mathrm{D}$ and the corresponding dietary requirements or treatment regimen suitable to the given disease.

\section{Vitamin D and pulmonary fibrosis}

Recently, it has been demonstrated that high levels of vitamin D (directly activated by respiratory tract cells through CYP27B1) could reduce pulmonary fibrosis by decreasing the levels of pro-inflammatory cytokines (IL-1 beta) produced by pulmonary fibroblast cell lines in a mouse model of bleomycin-induced lung fibrosis [47]. In another study vitamin $\mathrm{D}$ administration prevented bleomycin-induced lung fibrosis in mice, by decreasing the levels of hydroxyproline and col1a1, col3a1, and alfa-SMA mRNAs [48]. In the same study, pretreatment with vitamin D reduced profibrotic stimuli and restored TGFB1-induced downregulation of VDR mRNA levels. Elsewhere, vitamin D deficiency proved to activate the RAS pathway with induction of TGF B-1 [49]. Another pathway inhibited by $1,25(\mathrm{OH} 2)$ vitamin
$\mathrm{D}[50]$ is the $\mathrm{Wnt} /$ beta-catenin signaling, which has also been reported as involved in pulmonary fibrosis.

\section{Discussion}

The demographics of the Covid-19 outbreak proves that elderly males, with or without comorbidities, are the most affected across all populations. The available data on the epidemic are also showing a lesser involvement of vast areas lying in the tropics. Although this could easily relate to the lower median age of the population of developing countries, it is harder to make such an inference when looking at the markedly slow march of the Covid-19 epidemic in countries of the southern hemisphere, such as Australia [51]. Just recently [52], it has been directly hypothesized that vitamin D supplementation could be used as a therapeutic combination in Covid-19, based on the epidemiology of the disease, and on the decreased vitamin D status observed in calves infected with bovine coronavirus [53].

In the emergency setting that followed the spread of the Covid-19 pandemic new therapeutics have been empirically administered on the basis of former experience in the management of diseases sharing a few similarities with Covid-19-associated ARDS, such as inflammatory autoimmune diseases. A growing interest in the role of tocilizumab, a monoclonal antibody directed against interleukin-6 (IL-6), which is commonly used in the treatment of rheumatoid arthritis, ensued the publication of works regarding its potential use in the prevention of severe cytokine release syndromes, such as in Car-T cell treated pediatric oncologic patients $[54,55]$. This so-called cytokine storm has been postulated and confirmed [56] as the main responsible for the lethal pulmonary involvement that is being observed in Covid-19 and was thoroughly studied in former 2009 SARS epidemic [57]. In order to confirm tocilizumab therapeutic potential in ventilator-assisted Covid-19 patients, a clinical trial is currently ongoing in China [58] and in Europe [59]. Just recently, normal to high blood levels of vitamin D proved to act synergistically with tocilizumab in patients with rheumatoid arthritis by suppressing IL-6 enhanced osteocyte-mediated osteoclastogenesis and reducing disease activity [60].

Although the data on Covid-19 survivors are still lacking, a further downside of the pandemic might be the development of pulmonary fibrosis, which has been widely described as a common complication of ARDS [61]. Here, vitamin D supplementation before and after the infection could play an antifibrotic role that yet need to be delved into.

Finally, we would highlight some points that should be further investigated. There is, in fact, a vast literature that shows how obesity in children is closely related with low levels of vitamin $\mathrm{D}$, reaching the prevalence of $92 \%$ in the United States. Interestingly, in a recent review, it was also 
showed that increased adipose tissue, altered adipocyte function and development of adipocyte hypertrophy is linked to an altered adipokine secretion profile, with increase in TNF-alpha, IL-6, and IL-1b levels. Even more interestingly, the study proved that patients receiving long-term vitamin $\mathrm{D}$ supplementation had a reduction in adipose tissue inflammation by inhibition of TNF-alpha activity [62].

Prepubertal children have generally lower androgen levels, with an elevated estrogen to androgen ratio. It has been demonstrated that low estrogen levels are related with an increased IL-1beta, IL-6, and TNF, increased activity of Th1 cells and high androgen levels are related with an increase in IL-1beta, IL-6, and a reduction in TNF, IFN-gamma, IL-4, IL-5, GATA3. It is also clear that sex hormones can differentially influence, along with other genetic polymorphisms and environmental factors, development of innate and adaptive immune responses. In a murine model, the hormonal changes of puberty upregulated the expression of genes associated with innate and adaptive immune responses in males and females, respectively [63]. It has also been demonstrated that high levels of vitamin D seem to reduce aromatase activity (which is in turn increased by high levels of pro-inflammatory cytokines levels), thus containing the effects related to increased peripheral estrogen metabolism, such as B cell overactivity. That means that low levels of vitamin D can increase the risk of developing autoimmune diseases in young women [64].

\section{Conclusion}

Till date, only one recent paper addressed the relationship between vitamin D levels and the clinical outcomes of patients with Covid-19 [65]. The author conducted a multinomial logistic regression to explore the association between serum 25(OH)D level and clinical outcomes of 212 cases with laboratory-confirmed infection of SARS-CoV2. Interestingly, serum $25(\mathrm{OH}) \mathrm{D}$ proved to be a predictor of severe (OR 0.126, $p<0.001$ ) and critical (OR 0.051, $p<0.001)$ Covid-19. A recent review proposes the supplementation of vitamin D in Covid-19 patients based on the promising findings of RCTs conducted in other viral infections [66]. According to the emerging relationship between vitamin D status and alleged Covid-19 infection, vitamin D supplementation has already been proposed elsewhere [67]. Although we do not assume that vitamin D plays a role in the pathogenesis of Covid-19, we do believe that its putative role in preventing or even treating the disease urgently needs to be further addressed. At the moment of writing, an interventional randomized clinical trial has been proposed at the University of Granada, with enrollment of 200 participants, proposing vitamin D supplementations (a single dose of 25,000 UI of vitamin D) in preventing and treating mild forms of suspected Covid-19 [68]. In a recent paper, it is assumed that vitamin D prophylaxis (without overdosing) could reduce, especially in patients with hypovitaminosis $\mathrm{D}$, the severity of illness caused by SARS-CoV-2 [69]. The importance of treating the hypovitaminosis D along with an early nutritional supplementation has been highlighted for the potential preventing role of malnutrition sequelae in these patients [70]. On the basis of the possible direct and indirect effect of vitamin D on immune system and cytokines production, we speculate a possible influence of this vitamin on the immunologic response to the virus and/or a modulating effect on the drugs being administered, namely hydroxychloroquine and anti-IL 6 and anti-IL 1 agents.

Author contributions Dr FMP conceptualized and designed the article, collected data, drafted the initial manuscript, and reviewed and revised the final manuscript. Dr MR conceptualized and designed the article, drafted and wrote the manuscript, and reviewed and revised the final manuscript. Dr DF conceptualized and designed the article, coordinated and supervised data and reviewed and revised the final manuscript. Dr MC critically reviewed the manuscript for important intellectual content. Dr PD reviewed the manuscript for important intellectual content. Prof PR reviewed the manuscript for important intellectual content. All authors approved the final manuscript as submitted and agree to be accountable for all aspects of the work.

Funding No funding was secured for this study.

\section{Compliance with ethical standards}

Conflict of interest The authors have no financial relationships relevant to this article and no conflict of interest to disclose.

Research involving human participants and/or animals This articledoes not contain any studies with human participants or animals performedby the sole author D. Fintini.

Informed consent For this type of study, informed consent is notrequired.

\section{References}

1. World Health Organization. Coronavirus disease (COVID-19) outbreak. https://www.who.int/emergencies/diseases/novel-coron avirus-2019/situation-reports. Accessed 11 Mar 2019

2. Remuzzi A, Remuzzi G (2020) COVID-19 and Italy: what next? Lancet. https://doi.org/10.1016/S0140-6736(20)30627 (Health Policy Online First, publ March 13)

3. Wu Z, McGoogan JM (2020) Characteristics of and Important Lessons From the Coronavirus Disease 2019 (COVID-19) Outbreak in China: Summary of a Report of 72314 Cases From the Chinese Center for Disease Control and Prevention [published online ahead of print, 2020 Feb 24]. JAMA. https://doi. org/10.1001/jama.2020.2648

4. Guan WJ, Ni ZY, Hu Y et al (2020) Clinical characteristics of Coronavirus Disease 2019 in China [published online ahead of print, 2020 Feb 28]. N Engl J Med. https://doi.org/10.1056/ NEJMoa2002032 
5. Lu X, Zhang L, Du H et al (2020) SARS-CoV-2 infection in children [published online ahead of print, 2020 Mar 18]. N Engl J Med. https://doi.org/10.1056/NEJMc2005073

6. Dong Y, Mo X, Hu Y et al (2020) Epidemiology of COVID-19 among children in China [published online ahead of print, 2020 Mar 16]. Pediatrics. https://doi.org/10.1542/peds.2020-0702

7. Holick MF (1678S) Sunlight and vitamin D for bone health and prevention of autoimmune diseases, cancers, and cardiovascular disease. Am J Clin Nutr 80(6 Suppl):1678S-S1688. https://doi. org/10.1093/ajen/80.6.1678S

8. Holick MF, Binkley NC, Bischoff-Ferrari HA, Gordon CM, Hanley DA, Heaney RP, Murad MH, Weaver CM (2011) Evaluation, treatment, and prevention of vitamin D deficiency: an endocrine society clinical practice guideline. J Clin Endocrinol Metab 96(7):1911-1930. https://doi.org/10.1210/jc.2011-0385

9. Munns CF, Shaw N, Kiely M et al (2016) Global consensus recommendations on prevention and management of nutritional rickets. Horm Res Paediatr 85(2):83-106. https://doi.org/10.1159/00044 3136

10. Rossi P, Chini L, Fattorossi A et al (1987) 1,25-Dihydroxyvitamin D3 and phorbol esters (TPA) may induce select in vitro differentiation pathways in the HL60 promyelocytic cell line. Clin Immunol Immunopathol 44(3):308-16

11. Baeke F, Takiishi T, Korf H, Lemire JM, Archer DC, Beck L, Spielberg HL et al (1995) Vitamin D: modulator of the immune system. Immunosuppressive actions of 1,25-dihydroxyvitamin D3: preferential inhibitions of Th1 functions. J Nutr 125:1704-8

12. Lemire JM (1992) Immunomodulatory role of 1,25-dihydroxyvitamin D3. J Cell Biochem 49(1):26-31. https://doi.org/10.1002/ jcb.240490106

13. Liu PT, Stenger S, Li H et al (2006) Toll-like receptor triggering of a vitamin D-mediated human antimicrobial response. Science 311(5768):1770-1773. https://doi.org/10.1126/science.1123933

14. Teymoori-Rad M, Shokri F, Salimi V, Marashi SM (2019) The interplay between vitamin D and viral infections. Rev Med Virol 29(2):e2032. https://doi.org/10.1002/rmv.2032[6]

15. Hsieh E, Yin MT (2018) Continued interest and controversy: vitamin D in HIV. Curr HIV/AIDS Rep 15(3):199-211. https://doi. org/10.1007/s11904-018-0401-4

16. Alvarez N, Aguilar-Jimenez W, Rugeles MT (2019) The potential protective role of vitamin D supplementation on HIV-1 infection. Front Immunol 10:2291. https://doi.org/10.3389/fimmu 2019.02291

17. Eckard AR, O'Riordan MA, Rosebush JC (2018) Vitamin D supplementation decreases immune activation and exhaustion in HIV-1-infected youth. Antivir Ther 23(4):315-324. https://doi. org/10.3851/IMP3199

18. Mahon BD, Wittke A, Weaver V, Cantorna MT (2003) The targets of vitamin $\mathrm{D}$ depend on the differentiation and activation status of CD4-positive T-cells. J Cell Biochem 89:922-932

19. Zhang Y, Leung DY, Richers BN et al (2012) Vitamin D inhibits monocyte/macrophage proinflammatory cytokine production by targeting MAPK phosphatase-1. J Immunol 188:2127-2135. https ://doi.org/10.4049/jimmunol.1102412

20. Chen S, Sims GP, Chen XX, Gu YY, Chen S, Lipsky PE (2007) Modulatory effects of 1,25-dihydroxyvitamin D3 on human B cell differentiation. J Immunol 179:1634-1647

21. https://www.who.int/news-room/fact-sheets/detail/pneumonia. Accessed 2 Aug 2019

22. Zhou YF, Luo BA, Qin LL (2019) The association between vitamin $\mathrm{D}$ deficiency and community-acquired pneumonia: a meta-analysis of observational studies. Medicine (Baltimore) 98(38):e17252. https://doi.org/10.1097/MD.0000000000017252

23. Gruber-Bzura BM (2018) Vitamin D and influenza-prevention or therapy? Int J Mol Sci 19(8):2419. https://doi.org/10.3390/ijms1 9082419 (Published 2018 Aug 16)
24. Zdrenghea MT, Makrinioti H, Bagacean C, Bush A, Johnston SL, Stanciu LA (2017) Vitamin D modulation of innate immune responses to respiratory viral infections. Rev Med Virol. https:// doi.org/10.1002/rmv.1909

25. Martineau AR, Jolliffe DA, Hooper RL et al (2017) Vitamin D supplementation to prevent acute respiratory tract infections: systematic review and meta-analysis of individual participant data. BMJ 356:i6583. https://doi.org/10.1136/bmj.i6583 (Published 2017 Feb 15)

26. Esposito S, Lelii M (2015) Vitamin D and respiratory tract infections in childhood. BMC Infect Dis 15:487. https://doi. org/10.1186/s12879-015-1196-1

27. Das RR, Singh M, Naik SS (2018) Vitamin D as an adjunct to antibiotics for the treatment of acute childhood pneumonia. Cochrane Database Syst Rev 7(7):CD011597. https://doi. org/10.1002/14651858.CD011597.pub2 (Published 2018 Jul 19)

28. Del-Rio-Navarro BE, Espinosa Rosales F, Flenady V, SienraMonge JJ (2006) Immunostimulants for preventing respiratory tract infection in children. Cochrane Database Syst Rev. https:// doi.org/10.1002/14651858.CD004974.pub2 (Published 2006 Oct 18)

29. Aglipay M, Birken CS, Parkin PC et al (2017) Effect of highdose vs standard-dose wintertime vitamin $\mathrm{D}$ supplementation on viral upper respiratory tract infections in young healthy children. JAMA 318(3):245-254. https://doi.org/10.1001/jama.2017.8708

30. Pletz MW, Terkamp C, Schumacher U et al (2014) Vitamin D deficiency in community-acquired pneumonia: low levels of $1,25(\mathrm{OH}) 2 \mathrm{D}$ are associated with disease severity. Respir Res 15(1):53. https://doi.org/10.1186/1465-9921-15-53 (Published 2014 Apr 27)

31. Miroliaee AE, Salamzadeh J, Shokouhi S, Sahraei Z (2018) The study of vitamin D administration effect on CRP and interleukin-6 as prognostic biomarkers of ventilator associated pneumonia. $\mathrm{J}$ Crit Care 44:300-305. https://doi.org/10.1016/j.jcrc.2017.08.040

32. Altieri B, Muscogiuri G, Barrea L et al (2017) Does vitamin D play a role in autoimmune endocrine disorders? A proof of concept. Rev Endocr Metab Disord. https://doi.org/10.1007/s1115 4-016-9405-9

33. Skaaby T, Husemoen LL, Thuesen BH, Linneberg A (2015) Prospective population based study of the association between vitamin D status and incidence of autoimmune disease. Endocrine 50:231-238

34. Xiong J, He Z, Zeng X, Zhang Y, Hu Z (2014) Association of vitamin $D$ receptor gene polymorphisms with systemic lupus erythematosus: a meta-analysis. Clin Exp Rheumatol 32:174-181

35. Mosaad YM, Hammad EM, Fawzy Z et al (2014) Vitamin D receptor gene polymorphism as possible risk factor in rheumatoid arthritis and rheumatoid related osteoporosis. Hum Immunol 75:452-461

36. Bizzaro G, Antico A, Fortunato A, Bizzaro N (2017) Vitamin D and autoimmune diseases: is vitamin $\mathrm{D}$ receptor (VDR) polymorphism the culprit? Isr Med Assoc J 19(7):438-443

37. Amital H, Szekanecz Z, Szucs G et al (2010) Serum concentrations of 25-OH vitamin D in patients with systemic lupus erythematosus (SLE) are inversely related to disease activity: is it time to routinely supplement patients with SLE with vitamin D? Ann Rheum Dis 69:1155-1157

38. Ilescas-Montes R, Melguizo-Rodríguez L, Ruiz C et al (2019) Vitamin D and autoimmune diseases 2019. Life Sci 233:116744. https://doi.org/10.1016/j.lfs.2019.116744

39. Zerr P, Vollath S, Palumbo-Zerr K et al (2015) Vitamin D receptor regulates TGF- $\beta$ signalling in systemic sclerosis. Ann Rheum Dis 74(3):e20. https://doi.org/10.1136/annrheumdis-2013-204378

40. Chandrashekara S, Patted A (2017) Role of vitamin D supplementation in improving disease activity in rheumatoid arthritis: 
an exploratory study. Int J Rheum Dis 20(7):825-831. https://doi. org/10.1111/1756-185X.12770

41. Aslam MM, John P, Bhatti A, Jahangir S, Kamboh MI (2019) Vitamin D as a principal factor in mediating rheumatoid arthritis-derived immune response. Biomed Res Int. https://doi. org/10.1155/2019/3494937(Published 2019 May 7)

42. Sengler C, Zink J, Klotsche J et al (2018) Vitamin D deficiency is associated with higher disease activity and the risk for uveitis in juvenile idiopathic arthritis-data from a German inception cohort. Arthritis Res Ther 20(1):276

43. Finch SL, Rosenberg AM, Vatanparast H (2018) Vitamin D and juvenile idiopathic arthritis. Pediatr Rheumatol Online J 16(1):34 (Published 2018 May 16)

44. Verdoni L, Mazza A, Gervasoni A et al (2020) An outbreak of severe Kawasaki-like disease at the Italian epicentre of the SARSCoV-2 epidemic: an observational cohort study [published online ahead of print, 2020 May 13]. Lancet. https://doi.org/10.1016/ S0140-6736(20)31103-X

45. Stagi S, Rigante D, Lepri G, Matucci Cerinic M, Falcini F (2016) Severe vitamin D deficiency in patients with Kawasaki disease: a potential role in the risk to develop heart vascular abnormalities? Clin Rheumatol 35(7):1865-1872

46. Jun JS, Jung YK, Lee DW (2017) Relationship between vitamin $\mathrm{D}$ levels and intravenous immunoglobulin resistance in Kawasaki disease. Korean J Pediatr 60(7):216-220. https://doi.org/10.3345/ kjp.2017.60.7.216

47. Tsujino I, Ushikoshi-Nakayama R, Yamazaki T, Matsumoto N, Saito I (2019) Pulmonary activation of vitamin D3 and preventive effect against interstitial pneumonia. J Clin Biochem Nutr 65(3):245-251. https://doi.org/10.3164/jcbn.19-48

48. Tzilas V, Bouros E, Barbayianni I et al (2019) Vitamin D prevents experimental lung fibrosis and predicts survival in patients with idiopathic pulmonary fibrosis. Pulm Pharmacol Ther 55:17-24. https://doi.org/10.1016/j.pupt.2019.01.003

49. Shi Y, Liu T, Yao L et al (2017) Chronic vitamin D deficiency induces lung fibrosis through activation of the renin-angiotensin system. Sci Rep 7(1):3312. https://doi.org/10.1038/s41598-01703474-6(Published 2017 Jun 12)

50. Pendás-Franco N, Aguilera O, Pereira F, González-Sancho JM, Muñoz A (2008) Vitamin D and Wnt/beta-catenin pathway in colon cancer: role and regulation of DICKKOPF genes. Anticancer Res 28(5A):2613-2623

51. COVID-19 National Incident Room Surveillance Team (2020) COVID-19, Australia: Epidemiology Report 6 (Reporting week ending 19:00 AEDT 7 March 2020). Commun Dis Intell (2018). https://doi.org/10.33321/cdi.2020.44.21(Published 2020 Mar 11)

52. Zhang L, Liu Y (2020) Potential interventions for novel coronavirus in China: a systematic review. J Med Virol 92(5):479-490. https://doi.org/10.1002/jmv.25707

53. Nonnecke BJ, McGill JL, Ridpath JF, Sacco RE, Lippolis JD, Reinhardt TA (2014) Acute phase response elicited by experimental bovine diarrhea virus (BVDV) infection is associated with decreased vitamin D and E status of vitamin-replete preruminant calves. J Dairy Sci 97:5566-5579

54. Myers RM, Kadauke S, Li Y, Callahan CA, Gladney W, Fitzgerald JC, McGuire R (2020) Risk-adapted preemptive tocilizumab decreases severe cytokine release syndrome (CRS) after CTL019 CD19-targeted chimeric antigen receptor (CAR) T-cell therapy for pediatric B-cell acute lymphoblastic leukemia (B-ALL). Biol Blood Marrow Transplant 26(3):S39

55. Tanaka T, Narazaki M, Kishimoto T (2016) Immunotherapeutic implications of IL-6 blockade for cytokine storm. Immunotherapy 8(8):959-970. https://doi.org/10.2217/imt-2016-0020

56. Pedersen SF, Ho YC (2020) SARS-CoV-2: a storm is raging [published online ahead of print, 2020 Mar 27]. J Clin Investig. https ://doi.org/10.1172/JCI137647
57. Channappanavar R, Perlman S (2017) Pathogenic human coronavirus infections: causes and consequences of cytokine storm and immunopathology. Semin Immunopathol 39(5):529-539. https:// doi.org/10.1007/s00281-017-0629-x

58. ClinicalTrials.gov [Internet]. Bethesda (MD): National Library of Medicine (US). 2020 Mar 8-Identifier NCT04306705, Tocilizumab vs CRRT in Management of Cytokine Release Syndrome (CRS) in COVID-19 (TACOS); 2020 Mar 12; [about 4 screens]. https://clinicaltrials.gov/ct2/show/NCT04306705? cond=tocil izumab+AND+covid\&draw $=2 \&$ rank $=1$. Accessed 15 Mar 2020

59. ClinicalTrials.gov [Internet]. Bethesda (MD): National Library of Medicine (US). 2020 Mar 20-Identifier NCT04317092, Multicenter Study on the Efficacy and Tolerability of Tocilizumab in the Treatment of Patients With COVID-19 Pneumonia (TOCIVID-19); 2020 Mar 20; [about 5 screens]. https ://clinicaltrials.gov/ct2/show/NCT04317092?cond=TOCIV ID\&draw $=2 \&$ rank=1. Accessed 20 Mar 2020

60. Kim H, Baek S, Hong SM et al (2020) 1,25-Dihydroxy vitamin D3 and interleukin- 6 blockade synergistically regulate rheumatoid arthritis by suppressing interleukin-17 production and osteoclastogenesis. J Korean Med Sci 35(6):e40. https://doi.org/10.3346/ jkms.2020.35.e40

61. Thompson BT, Chambers RC, Liu KD (2017) Acute respiratory distress syndrome. N Engl J Med 377(19):1904-1905. https://doi. org/10.1056/NEJMc1711824

62. Zacharova I, Klimov L, Kuryaninova V et al (2019) Vitamin D insufficiency in overweight and obese children and adolescents. Front Endocrinol. https://doi.org/10.3389/fendo.2019.00103

63. Klein SL, Flanagan KL (2016) Sex differences in immune responses. Nat Rev Immunol 16(10):626-638. https://doi. org/10.1038/nri.2016.90

64. Cuotolo M, Paolino S, Sulli A et al (2014) Vitamin D, steroid hormones, and autoimmunity. Ann N Y Acad Sci 1317:39-46. https://doi.org/10.1111/nyas.12432

65. Alipio M (2020) Vitamin D supplementation could possibly improve clinical outcomes of patients infected with Coronavirus-2019 (COVID-19). Available at SSRN: https://ssrn.com/abstr act $=3571484$ or https://doi.org/10.2139/ssrn.3571484

66. Grant WB, Lahore H, McDonnell SL et al (2020) Evidence that vitamin D supplementation could reduce risk of influenza and COVID-19 infections and deaths. Nutrients 12(4):E988. https:// doi.org/10.3390/nu12040988

67. McCartney DM, Byrne DG (2020) Optimisation of vitamin D status for enhanced immuno-protection against Covid-19. Ir Med J 113(4):58

68. ClinicalTrials.gov [Internet]. Bethesda (MD): National Library of Medicine (US). 2020 Apr 3-Identifier NCT04334005, Effect of Vitamin D Administration on Prevention and Treatment of Mild Forms of Suspected Covid-19 (COVITD-19), 2020 Apr 7; [about 3 screens]. https://clinicaltrials.gov/ct2/show/NCT04334005. Accessed 13 Apr 2020

69. Panarese A, Shaini E (2020) Letter: Covid-19, and vitamin D. Aliment Pharmacol Ther. https://doi.org/10.1111/apt.15752

70. Caccialanza R, Laviano A, Lobascio F et al (2020) Early Nutritional supplementation in non-critically ill patients hospitalized for the 2019 novel coronavirus disease (COVID-19): rationale and feasibility of a shared pragmatic protocol. Nutrition. https://doi. org/10.1016/j.nut.2020.110835

Publisher's Note Springer Nature remains neutral with regard to jurisdictional claims in published maps and institutional affiliations. 